\title{
QUANTITATIVE PREDICTION OF BEEF QUALITY USING VISNIR SPECTROSCOPY WITH LARGE DATA SAMPLES UNDER INDUSTRY CONDITIONS
}

Date of submission: 17/03/2014

\section{Tong Qiao ${ }^{a}$, Jinchang Ren ${ }^{\mathrm{b} *}$, Cameron Craigie ${ }^{\mathrm{c}, \mathrm{e}}$, Jaime Zabalza ${ }^{\mathrm{d}}$, Charlotte Maltin ${ }^{\mathrm{c}, \mathrm{g}}$, Stephen Marshall ${ }^{\mathrm{f}}$}

${ }_{a, b, d, f}$ Centre for Excellence in Signal and Image Processing (CeSIP), Dept. of Electronic and Electrical Engineering, University of Strathclyde, 204 George Street, Glasgow, G1 1XW, UK.

${ }^{c}$ Quality Meat Scotland, Rural Centre, West Mains, Ingliston Newbridge, EH28 8NZ, UK.

${ }^{e}$ Current Address: AgResearch Ruakura, 10 Bisley Road. Private Bag 3115, Hamilton 3240, New Zealand.

${ }^{g}$ Current address: Biomics Ltd, Inverurie, Aberdeenshire, AB51 OLE, UK.

${ }^{a}$ E-mail:t.qiao@strath.ac.uk.

${ }^{b}$ E-mail: jinchang.ren@strath.ac.uk, tel. +44-141-5482384 for corresponding author Dr. Ren.

${ }^{e}$ E-mail:cameron.craigie@agresearch.co.nz.

${ }^{d}$ E-mail:j.zabalza@strath.ac.uk.

${ }^{g}$ E-mail:c.maltin@biomics.co.uk.

${ }^{f}$ E-mail: stephen.marshall@strath.ac.uk.

It is well known that the eating quality of beef has a significant influence on the repurchase behavior of consumers. There are several key factors which affect the perception of quality including color, tenderness, juiciness and flavor. To support consumers repurchase choices, there is a need for an objective measurement of quality that could be applied to meat prior to its sale. Objective approaches such as offered by spectral technologies may be useful, but the analytical algorithms used remain to be optimized. For visible and near infrared (VISNIR) spectroscopy, Partial Least Squares Regression (PLSR) is a widely used technique for meat related quality modeling and prediction. In this paper, a Support Vector Machine (SVM) based machine learning approach is presented to predict beef eating quality traits. Although SVM has been successfully used in various disciplines, it has not been applied extensively in the analysis of meat quality parameters. To this end, the performance of PLSR and SVM as tools for the analysis of meat tenderness is evaluated, using a large dataset acquired under industrial conditions. The spectral dataset was collected using VISNIR spectroscopy with the wavelength ranging from $350 \mathrm{~nm}$ to $1800 \mathrm{~nm}$ on 234 beef M. longissimus thoracis steaks from heifers, steers and young bulls. As the dimensionality with the VISNIR data is very high (over 1600 spectral bands), the Principal Component Analysis (PCA) technique was applied for feature extraction and data reduction. The extracted principal components (less than 100) were then used for data modeling and prediction. The prediction results showed that SVM has a greater potential to predict beef eating quality than PLSR, especially for the prediction of tenderness. The influence of animal gender on beef quality prediction was also investigated, and it was found that beef quality traits were predicted most accurately in beef from young bulls.

Keywords: Visible and near infrared spectroscopy, beef quality, principal component analysis, support vector machine, partial least squares regression. 
Introduction. Visible and near infrared (VISNIR) spectroscopy has been recognized as a rapid, low cost and non-destructive tool for determining food chemical composition [1]. Over the past thirty years, it has been applied in the meat industry for prediction of meat quality [2]. The visible spectrum is part of the electromagnetic spectrum (EMS) which is visible to human eyes, lying between $390 \mathrm{~nm}$ to $700 \mathrm{~nm}$ [3]. The NIR spectrum, whose wavelength ranges in $780 \mathrm{~nm}-2500 \mathrm{~nm}$, is just between the visible and infrared region [4].

Compared with conventional approaches to assess meat quality, VISNIR spectroscopy has many advantages. In addition to being non-destructive, it requires minimal sample preparation, needs no reagents and produces no waste [5]. It is also suitable for on-line application where the rapidity of measurement allows the determination of several different attributes at the same time. As a result, efforts have been focused on the use of the VISNIR spectroscopy for predicting different meat quality traits, including meat color in the Commision Internationale de 1'Eclairage (CIE) L*, a* and $\mathrm{b}^{*}$ color space, ultimate $\mathrm{pH}$, Warner-Bratzler shear force (WBSF) and slice shear force (SSF) [6-9].

Three key factors, including tenderness, juiciness and flavor, contribute to the consumer perception of satisfactory meat quality [10]. Although surface color and ultimate $\mathrm{pH}$ can influence the beef shelf life, tenderness was found to be the most critical issue that affects the re-purchasing behavior of customers [11]. Tenderness is commonly measured by Warner-Bratzler shear force or slice shear force (SSF) [12]. Absolute trait values can be predicted using VISNIR spectroscopy and the performance of prediction is evaluated by the coefficient of determination $\left(\mathrm{R}^{2}\right)$ and the ratio of performance deviation (RPD) [11, 13-15].

Various statistical regression approaches can be used to construct calibration equations, including multiple linear regression (MLR), partial and modified partial least squares regression (PLSR), principal component regression (PCR) and neural networks [16]. Partial least squares regression is the most common method to construct calibration models from VISNIR spectra for the prediction of sensory parameters in meat [7, 17-19]. The PLSR model establishes a relationship between independent spectral variables $\mathrm{X}$ and the dependent quality trait variable $\mathrm{Y}$ where data in $\mathrm{X}$ is projected onto a few latent vectors called PLS components [20]. However, PLSR is based on the linear algorithm so that the best performance can only be achieved when there is a linear relationship between spectra and quality trait values [21], which might not be the case in every situation. In contrast, SVM based learning approaches are based on statistical learning theory and are effective in prediction of both linear and non-linear data [22]. Despite this, there has been limited research to validate the performance of SVM to predict beef quality traits with VISNIR spectroscopy, especially with large datasets collected under industrial conditions. The advantages of SVM over other methods are that it does not require large quantities of samples to construct the calibration model and it is not affected by sample outliers [23].

The objective of this paper was to assess the use of SVM for the prediction of beef quality parameters, including surface color, ultimate $\mathrm{pH}$ and SSF, using VISNIR spectroscopy. The performance of SVM was compared with results predicted using PLSR, in a similar manner to those reported by Craigie [24].

Materials and methods. Beef sample preparation and spectra collection. A total of 234 cattle below 30 months of age, comprising 75 heifers, 118 steers and 41 young bulls, were randomly selected in a Scottish abattoir over a 10 -week period. The mean hot carcass weight was $332.6 \mathrm{~kg}$, which is similar to the average carcass weight $(341.7 \mathrm{~kg})$ of steers, heifers and young bulls slaughtered in UK in January 2014 [25]. The VISNIR dataset were acquired as part of another experiment, where PLSR was used for beef quality prediction [24]. All 234 carcasses were quartered between the $10^{\text {th }}$ and $11^{\text {th }}$ ribs at 48 hours post mortem into hind and forequarters. A $2.54 \mathrm{~cm}$ piece of beef sample containing the $M$. longissimus thoracis, associated muscles and subcutaneous fat, was removed from the $11^{\text {th }}$ rib section of each carcass at quartering. After 2 minutes of blooming [11], 10 replicate scans were randomly collected from different sites on the cut surface using an ASD Quality spec Pro VISNIR spectrometer with a fiber-optic probe $(\lambda=350 \mathrm{~nm}-1800 \mathrm{~nm}$ at $1 \mathrm{~nm}$ intervals $)$. For 
VISNIR spectroscopy to measure meat and meat products, reflectance (R) is usually converted to absorbance $(1 / \mathrm{R})$ by logarithm transformation, linearizing the relationship between the concentration of an absorbing compound and the absorption spectrum [17]. A calibration reference is required to determine the corresponding wavelengths where absorption occurs. Dividing the reflected spectrum by the white reference spectrum, $R$ can be acquired, as shown in Equation (1), where $I$ and $I_{0}$ are the intensity of the reflected spectrum and the white reference respectively. The calibration is achieved by using a white calibration tile which reflects $100 \%$ of the radiation at all VISNIR wavelengths [4].

$$
R=\frac{I}{I_{0}}
$$

Meat quality measurements. Once the spectral information of the steak was acquired, ultimate $\mathrm{pH}\left(\mathrm{pH}_{\mathrm{u}}\right)$ was determined with a Testo $205 \mathrm{pH}$ meter. The color of $M$. longissimus lumborum was measured in the L*a*b* scale with a Minolta CR-410 colorimeter after allowing the surface to bloom for 45 minutes, where $\mathrm{L}^{*}$ is the lightness, $\mathrm{a}^{*}$ is the redness and $\mathrm{b}^{*}$ is the yellowness. Steaks were sealed in plastic bags, transported at $4^{\circ} \mathrm{C}$ to the laboratory and stored overnight at $3^{\circ} \mathrm{C}$. The following day (3 days post mortem), steaks were cooked on a clam-shell grill until the internal temperature reached $71^{\circ} \mathrm{C}$, using a stainless steel temperature meter (Hanna HI-98509 Checktemp 1). Once cooked, a $50 \mathrm{~mm} \times 10 \mathrm{~mm}$ slice of steak was sheared orthogonal to the muscle fiber axis using a Lloyd TA-plus texture analyzer fitted with a flat blunt-end blade. Then the peak SSF was extracted from the force deformation curve.

Data processing. VISNIR spectra were transformed into absorbance log, and 10 replicates of VISNIR spectra of one steak sample are plotted in Figure 1. As shown in the plot, excessive noise exists in the extreme parts of the spectra, which is illustrated in dotted lines. Removing this noise resulted in $495 \mathrm{~nm}-1600 \mathrm{~nm}$ as the working spectra plotted in solid lines. The median of 10 replicates was used to represent the spectral profile of each steak.

For VISNIR spectral data, the high dimensionality is a major problem and SVM is sensitive to the curse of dimensionality [26]. Therefore, feature selection is expected to reduce the dimensionality by mapping the data to a new space where differentiability is higher in a subset of the transformed features than in any subset of the original data [5]. The feature reduction technique used in the project is principal component analysis (PCA), where the covariance matrix is given by:

$$
\boldsymbol{S}_{T}=\sum_{k=1}^{n}\left(\boldsymbol{x}_{k}-\boldsymbol{\mu}\right)\left(\boldsymbol{x}_{k}-\boldsymbol{\mu}\right)^{T}
$$

where $\boldsymbol{S}_{T}$ is an $\mathrm{N}$ by N covariance matrix, $\boldsymbol{x}_{k}$ is an N-dimensional vector representing the absorbance values, $\boldsymbol{\mu}$ is the mean vector at each dimension, and $n$ is the total number of training data. The projection $\boldsymbol{W}_{\text {opt }}$ is chosen to maximise the determinant of the total covariance matrix of the projected samples, which is:

$$
\boldsymbol{W}_{\text {opt }}=\arg \max \left|\boldsymbol{W}^{T} \boldsymbol{S}_{T} \boldsymbol{W}\right|=\left[\begin{array}{llll}
\boldsymbol{w}_{1} & \boldsymbol{w}_{2} & \ldots & \boldsymbol{w}_{m}
\end{array}\right]
$$

where $\boldsymbol{w}_{i}$ is the set of $\mathrm{N}$-dimensional eigenvector of $\boldsymbol{S}_{T}$ corresponding to the $m$ largest eigenvalues. The value of $m$ was decided by trial and error.

With reduced dimensionality, it is easy for SVM to construct the prediction model. For the classification and regression problems, SVM maps the training vectors $\boldsymbol{x}$ into a m-dimensional space by using a nonlinear mapping function $\phi_{i}(\boldsymbol{x})$. After that, the SVM finds a linear separating hyperplane in the new feature space,

$$
f(\boldsymbol{x})=b+\sum_{i=1}^{m} w_{i} \phi_{i}(\boldsymbol{x})
$$

where $b, w_{1}, \ldots, w_{m}$ are the parameters to be adjusted [27]. Before training the model, scaling is required by SVM. In this paper, each attribute in both the training and testing sets was linearly scaled to the range from -1 to 1 . 
The most significant part of the SVM is its kernel function $K$ :

$$
K\left(\boldsymbol{x}, \boldsymbol{x}^{\prime}\right)=\sum_{i=1}^{m} \phi_{i}(\boldsymbol{x}) \phi_{i}\left(\boldsymbol{x}^{\prime}\right)
$$

The kernel function adopted in the paper is the radial basis function (RBF) kernel, given in Equation (6).

$$
K\left(\boldsymbol{x}, \boldsymbol{x}^{\prime}\right)=\exp \left(-\gamma\left\|\boldsymbol{x}-\boldsymbol{x}^{\prime}\right\|^{2}\right), \gamma>0
$$

Two parameters must be adjusted in the RBF kernel, which are the cost of error C and gamma $\gamma$. A grid search using a 4-fold cross-validation was employed to look for optimal values of $\mathrm{C}$ and $\gamma$ by trying exponentially growing sequences. For instance, $\mathrm{C}=2^{-10}, 2^{-9}, \ldots, 2^{14}, 2^{15}$ and $\gamma=2^{-15}, 2^{-14}, \ldots, 2^{9}$, $2^{10}$. Finally, the optimized prediction model was obtained.

The performance of SVM was compared with PLSR, where both models were constructed using Matlab. Similar to the dataset construction method used for PLSR by Craigie [24], steak samples were split into calibration (training) and validation (testing) datasets by sorting in ascending order separately for each trait. Every 4th sample was then selected for the validation set, with the intervening three samples being allocated to the calibration set, as recommended by Williams [28]. Accordingly, $75 \%$ of the whole dataset was assigned to the calibration set and the remaining $25 \%$ was assigned to the validation set. Thus, the validation set is representative of the calibration set with similar mean and standard deviation (SD). After the calibration data used for modeling were defined, the number of PLS components was chosen based on the full leave-one-out cross-validation where each sample is removed, predicted, and replaced in a sequential manner [29].

Results and discussion. Table 1 shows the mean, range, and SD of measured values for the parameters analyzed in the beef samples for the calibration and validation sets respectively.

SVM models were developed and cross validated on the calibration set and tested on the validation set without carrying out any spectral pre-treatment on the dataset. The performance of prediction is evaluated by the coefficient of determination $\left(\mathrm{R}^{2}\right)$ for both the calibration and validation sets, root mean squared error (RMSE) for calibration set, standard error of prediction (SEP) as well as the ratio of performance deviation (RPD) for validation set. The ratio of performance deviation is defined as below,

$$
R P D=\frac{S D}{S E P}
$$

where values higher than 2 indicate that the calibration model is suitable to use and values higher than 3 indicate a model adequate for analytical purposes [21].

In Table 2 and Table 3, results from the calibration and the validation datasets using both SVM and PLSR approaches are given for comparisons. It can be seen that, for the calibration results, SVM always shows a better performance than PLSR, where the $\mathrm{R}_{\text {val }}^{2}$ for SSF is more than double of that with PLSR.

The predictions of quality attributes in beef M. longissimus thoracis by NIR spectroscopy by other researchers are shown in Table 4. The results obtained by SVM in the current analysis were similar to (or even higher than) those above in predicting $\mathrm{L}^{*}$, which means the lightness $\mathrm{L}^{*}$ can be successfully predicted by SVM. For the predicting of $a^{*}$ and $b^{*}$, the results achieved had a RPD value between 1.45 1.56, which was much higher than those from Andrés et al. [6] and Prieto et al. [7]. For the prediction of $\mathrm{pH}_{\mathrm{u}}$, the $\mathrm{R}^{2}$ and $\mathrm{RPD}$ in the present study were only lower than those from Andrés ${ }^{6}$, probably due to the fact that the research by Andrés et al. [6] was conducted on 30 bulls, and meat from young bulls commonly has high ultimate $\mathrm{pH}_{\mathrm{u}}[24]$, thus a greater number of high $\mathrm{pH}$ readings in a dataset aids in the developments of a robust calibration model.

Most studies using VISNIR spectroscopy to assess beef tenderness use WBSF as the texture benchmark, while few published reports have attempted to predict SSF in beef. The results from 
SVM in the present study were quite low compared with those from WBSF based studies, possibly due to the tight commercial specification of the commercial cattle used. The calibration SD in the current dataset was only $16.8 \%$ of the difference of the maximum and minimum values of SSF parameter, indicating that the dataset was lacking a sufficiently large variation, which could be a possible reason of poor prediction.

As shown in the paper of Andrés et al. [6], prediction results obtained in young bulls seem to be quite favorable. Therefore, the prediction performance with different genders was investigated in the present study using SVM. The splitting method for calibration and validation datasets is the same as introduced previously, and the associated mean, data range, and SD of measure values for the parameters analyzed in the calibration and validation sets are compared in Table 5, Table 6 and Table 7, respectively. Despite occasional large differences in terms of the SD measurement caused by outliers, the data used for calibration and validation in each of the Tables 5-7 are statistically consistent in terms the mean and the data range covered. Moreover, the data distribution for heifers is very similar to steers, although young bulls appear to have lower values in $a^{*}, b^{*}$ and $L^{*}$. In addition, the mean ultimate $\mathrm{pH}$ values for the three genders are very close, whereas the associated mean SSF values are quite different.

The prediction results using SVM on three datasets from which the noise has been removed are shown in Table 8, Table 9 and Table 10. First, the calibrated SSF accuracy for heifers was the best and achieved over $96 \%$ in $\mathrm{R}^{2}$ measurement, followed by $71.5 \%$ for steers, whereas the result for young bulls was less than $30 \%$ due to large variations with the particular dataset. Second, the highest validation $\mathrm{R}^{2}$ of SSF achieved was approximately $27.3 \%$ from heifers, which was quite close to the results from Prieto et al. [30]. The results obtained from steers were low $\left(\mathrm{R}^{2}<6 \%\right)$, even though the calibrated $\mathrm{R}^{2}$ was over $70 \%$. In contrast, the validation $\mathrm{R}^{2}$ for young bulls achieved $15 \%$, although the calibration $\mathrm{R}^{2}$ was less than $30 \%$. In addition, comparing the RPD from three gender groups, it is noted that the prediction performance of young bull quality traits was much better than those of heifer and steer especially in predicting color parameters including $\mathrm{L}^{*}, \mathrm{a}^{*}$ and $\mathrm{b}^{*}$. This corroborated the high prediction accuracies obtained in bulls reported by Andrés et al. [6]. However, further analysis is required to investigate whether these results can be improved upon.

Conclusion. In this paper, VISNIR spectroscopy (350nm - 1800nm) was investigated for predicting of beef eating quality parameters, including color, ultimate $\mathrm{pH}$ and SSF. Due to the relatively high dimensionality of VISNIR spectra, PCA was applied for feature extraction and data reduction, followed by SVM based modeling and prediction. Applying models to external validation datasets, results achieved for the predictions of $\mathrm{L}^{*}, \mathrm{a}^{*}, \mathrm{~b}^{*}, \mathrm{pH}_{\mathrm{u}}$ and $\mathrm{SSF}$ in terms of $\mathrm{R}^{2}$ were $80.3 \%$, $63.7 \%, 53.6 \%, 73.6 \%$ and $19.8 \%$, respectively, where the corresponding RPD values were $2.19,1.56$, $1.45,1.92$ and 1.06. Although the predicted $\mathrm{R}^{2}$ values for SSF were quite low in comparison to other published data, overall, the results obtained by SVM were higher than those obtained by PLSR. This indicates that the prediction is strongly dependent on the data acquired, but SVM can play an important role in quantitatively predicting beef quality with VISNIR spectroscopy.

In addition, it was found that the quality traits of young bulls can be better predicted than those of heifers and steers, especially for the lightness $\mathrm{L}^{*}$, which indicates great potential for improved quality prediction using additional clues such as carcass gender.

Acknowledgement. This research is co-supported by the University of Strathclyde and Quality Meat Scotland. 


\section{REFERENCES}

1. B. G. Osborne, in Encyclopedia of Analytical Chemistry (2006).

2. N. Prieto, R. Roehe, P. Lavín, G. Batten and S. Andrés, Meat Sci., 83, 175-186 (2009).

3. C. Starr, Biology: concepts and applications, Wadsworth Publishing Company, Belmont, California (2005).

4. J. Workman and J. Shenk, Near-infrared spectroscopy in agriculture, American Society of Agronomy, Inc., Crop Science Society of America, Inc. and Soil Science Society of America, Inc., Madison, Wisconsin, USA (2004).

5. D. W. Sun, Hyperspectral imaging for food quality analysis and control, Elsevier (2010).

6. S. Andrés, A. Silva, A. Soares-Pereira, C. Martins, A. Bruno-Soares and I. Murray, Meat Sci., 78, 217-224 (2008).

7. N. Prieto, S. Andrés, F. J. Giráldez, A. R. Mantecón and P. Lavín, Meat Sci., 79, 692-699 (2008).

8. J. Yang, Q. Meng, L. Ren, Z. Zhou and X. Xie, Spectrosc. Spect. Anal., 30, 685 (2010).

9. K. Rosenvold, E. Micklander, P. W. Hansen, R. Burling-Claridge, M. Challies, C. Devine and M. North, Meat Sci., 82, 379-388 (2009).

10. L. E. Jeremiah and D. M. Phillips, Meat Sci., 55, 493-502 (2000).

11. S. D. Shackelford, T. L. Wheeler and M. Koohmaraie, Meat Sci., 69, 409-415 (2005).

12. D. A. King, T. L. Wheeler, S. D. Shackelford and M. Koohmaraie, Fresh meat texture and tenderness, Woodhead Publishing Limited, Cambridge, UK (2009).

13. B. Park, Y. R. Chen, W. R. Hruschka, S. D. Shackelford and M. Koohmaraie, J. Anim. Sci., 76, 2115-2120 (1998).

14. B. W. Moss, A. Gorden, K. Matthews, D. Homer and P. Hadley, Potential of NIR spectroscopy for prediction of tenderness of beef sirloin, Southport, UK (2009).

15. G. Ripoll, P. Alberti, B. Panea, J. L. Olleta and C. Sanudo, Meat Sci., 80, 697-702 (2008).

16. M. Prevolnik, M. Candek-Potokar and D. Skorjanc, Czech J. Anim. Sci., 49, 500-510 (2004).

17. S. R. Rust, D. M. Price, J. Subbiah, G. Kranzler, G. G. Hilton, D. L. Vanoverbeke and J. B. Morgan, J. Anim. Sci., 86, 211-219 (2008).

18. R. Rodbotten, B. H. Mevik and K. I. Hildrum, J. Near Infrared Spectrosc., 9, 199-210 (2001).

19. Y. L. Liu, B. G. Lyon, W. R. Windham, C. E. Realini, T. D. D. Pringle and S. Duckett, Meat Sci., 65, 1107-1115 (2001).

20. H. Abdi, in Encyclopedia for research methods for the social sciences, Thousand Oaks, CA: Sage, pp. 792-795 (2003).

21. M. Kamruzzaman, G. ElMasry, D. W. Sun and P. Allen, Anal. Chim. Acta., 714, 57-67 (2012).

22. I. Steinwart and A. Christmann, Support Vector Machines, Springer (2008).

23. C. J. C. Burges, Geometry and invariance in kernel based methods, MIT Press, Cambridge, MA (1999).

24. C. R. Craigie, Doctor of Philosophy, Massey University (2012).

25. S. Thompson, Department for Environment, Food \& Rural Affairs, York (2014).

26. Y. Bengio, O. Delalleau and N. Le Roux, The curse of dimensionality for local kernel machines, Report 1258, Departement d'informatique et recherche operationnelle, Universite de Montreal (2005).

27. P. Cortez, M. Portelinha, S. Rodrigues, V. Cadavez and A. Teixeira, Neural Process. Lett., 24, 41-51 (2006).

28. P. C. Williams, Near-infrared technology in the agricultural and food industries, American Association of Cereal Chemists, St. Paul, Minnesota, USA (2001).

29. T. Naes, T. Isakson, F. T. and T. Davies, Journal of Chemometrics, 2002, 17, 571-572.

30. N. Prieto, D. W. Ross, E. A. Navajas, G. R. Nute, R. I. Richardson, J. J. Hyslop, G. Simm and R. Roehe, Meat Sci., 2009, 83, 96-103. 
Table 1. Summary statistics of the quality attributes of 234 carcasses.

\begin{tabular}{|c|c|c|c|c|c|c|c|c|}
\hline \multirow[t]{2}{*}{ Trait } & \multicolumn{4}{|c|}{ Calibration } & \multicolumn{4}{|c|}{ Validation } \\
\hline & $\mathrm{n}$ & Mean & Range & SD & $\mathrm{n}$ & Mean & Range & SD \\
\hline $\mathrm{L}^{*}$ & 175 & 37.38 & $30.64-45.39$ & 2.54 & 59 & 37.30 & $27.65-44.32$ & 2.78 \\
\hline$a^{*}$ & 175 & 24.55 & $18.06-32.05$ & 2.41 & 59 & 24.46 & $14.88-31.40$ & 2.67 \\
\hline$b^{*}$ & 175 & 9.05 & $3.70-13.99$ & 1.96 & 59 & 9.01 & $2.74-13.95$ & 2.06 \\
\hline $\mathrm{pH}_{\mathrm{u}}$ & 175 & 5.52 & $5.20-6.74$ & 0.23 & 59 & 5.52 & $5.18-6.49$ & 0.23 \\
\hline SSF & 175 & 123.37 & $72.77-329.39$ & 42.46 & 59 & 123.61 & $69.83-312.00$ & 44.75 \\
\hline
\end{tabular}

Table 2. Performance of NIR spectroscopy for predicting instrumental meat quality in beef M. longissimus thoracis using SVM and PLSR in the calibration dataset, with noise removed spectra (495nm - 1800nm).

\begin{tabular}{|c|c|c|c|c|c|c|c|c|}
\hline \multirow[t]{2}{*}{ Trait } & \multicolumn{4}{|c|}{ SVM for data modeling } & \multicolumn{4}{|c|}{ PLSR for data modeling } \\
\hline & $\mathrm{n}$ & $\mathrm{PC}$ & $\mathrm{R}_{\text {cal }}^{2}(\%)$ & $\mathrm{RMSE}_{\text {cal }}$ & $\mathrm{n}$ & PLSC & $\mathrm{R}_{\text {cal }}^{2}(\%)$ & $\mathrm{RMSE}_{\mathrm{cal}}$ \\
\hline $\mathrm{L}^{*}$ & 175 & 10 & 83.4 & 1.05 & 175 & 11 & 83.2 & 1.04 \\
\hline$a^{*}$ & 175 & 45 & 69.6 & 1.34 & 175 & 10 & 55.3 & 1.60 \\
\hline$b^{*}$ & 175 & 25 & 66.7 & 1.13 & 175 & 10 & 64.3 & 1.17 \\
\hline $\mathrm{pH}_{\mathrm{u}}$ & 175 & 50 & 90.0 & 0.07 & 175 & 13 & 76.9 & 0.11 \\
\hline SSF & 175 & 10 & 88.7 & 14.66 & 175 & 5 & 16.1 & 38.79 \\
\hline
\end{tabular}

Table 3. Performance of NIR spectroscopy for predicting instrumental meat quality in beef M. longissimus thoracis using SVM and PLSR in the validation dataset, with noise removed spectra (495nm-1800nm).

Trait SVM for data prediction $\quad$ PLSR for data prediction

\begin{tabular}{|c|c|c|c|c|c|c|c|c|c|c|}
\hline & $\mathrm{n}$ & $\mathrm{PC}$ & $\mathrm{R}_{\text {val }}^{2}(\%)$ & $\mathrm{SE}_{\mathrm{val}}$ & $\mathrm{RPD}_{\text {val }}$ & $\mathrm{n}$ & PLSC & $\mathrm{R}_{\text {val }}^{2}(\%)$ & $\mathrm{SE}_{\mathrm{val}}$ & $\mathrm{RPD}_{\text {val }}$ \\
\hline $\mathrm{L}^{*}$ & 59 & 10 & 80.3 & 1.27 & 2.19 & 59 & 11 & 76.2 & 1.37 & 2.03 \\
\hline$a^{*}$ & 59 & 45 & 63.7 & 1.71 & 1.56 & 59 & 10 & 59.7 & 1.71 & 1.56 \\
\hline$b^{*}$ & 59 & 25 & 53.6 & 1.42 & 1.45 & 59 & 10 & 52.8 & 1.43 & 1.44 \\
\hline $\mathrm{pH}_{\mathrm{u}}$ & 59 & 50 & 73.6 & 0.12 & 1.92 & 59 & 13 & 67.1 & 0.13 & 1.77 \\
\hline SSF & 59 & 10 & 19.8 & 42.40 & 1.06 & 59 & 5 & 7.6 & 43.39 & 1.03 \\
\hline
\end{tabular}


Table 4. Publications for predicting instrumental meat quality in beef M. longissimus thoracis by NIR spectroscopy.

\begin{tabular}{|c|c|c|c|c|c|c|}
\hline Reference & Sex & Age & Weight & Trait & $\mathrm{R}_{\text {val }}^{2}(\%)$ & $\mathrm{RPD}_{\mathrm{val}}$ \\
\hline \multirow[t]{7}{*}{ [6] } & Bull & $\begin{array}{l}9-11 \\
\text { months }\end{array}$ & $90-150 \mathrm{~kg}$ & $\mathrm{~L}_{\mathrm{t} 0} *$ (No blooming) & $80 \%$ & 2.22 \\
\hline & & & & $\mathrm{L}_{\mathrm{t} 60} *($ Blooming for $1 \mathrm{~h})$ & $75 \%$ & 2.07 \\
\hline & & & & $\mathrm{a}_{\mathrm{t} 0} *$ (No blooming) & $23 \%$ & 1.14 \\
\hline & & & & $\mathrm{a}_{\mathrm{t} 60} *$ (Blooming for $\left.1 \mathrm{~h}\right)$ & $29 \%$ & 0.90 \\
\hline & & & & $\mathrm{b}_{\mathrm{t} 0} *$ (No blooming) & $27 \%$ & 1.17 \\
\hline & & & & $\mathrm{b}_{\mathrm{t} 60} *$ (Blooming for $\left.1 \mathrm{~h}\right)$ & $75 \%$ & 2.07 \\
\hline & & & & $\mathrm{pH}_{\mathrm{u}}$ & $91 \%$ & 3.17 \\
\hline \multirow[t]{8}{*}{ [7] } & Steer & 53 months & $813 \mathrm{~kg}$ & $\mathrm{~L}^{*}$ & $58.5 \%$ & 1.24 \\
\hline & & & & $a^{*}$ & $0.8 \%$ & 0.98 \\
\hline & & & & $b^{*}$ & $34.5 \%$ & 1.16 \\
\hline & & & & $\mathrm{pH}_{\mathrm{u}}$ & $41.0 \%$ & 1.12 \\
\hline & N/A & $\begin{array}{l}11.6 \\
\text { months }\end{array}$ & $442.5 \mathrm{~kg}$ & $\mathrm{~L}^{*}$ & $86.9 \%$ & 2.17 \\
\hline & & & & $a^{*}$ & $70.7 \%$ & 1.58 \\
\hline & & & & $b^{*}$ & $90.1 \%$ & 2.51 \\
\hline & & & & $\mathrm{pH}_{\mathrm{u}}$ & $47.2 \%$ & 1.26 \\
\hline [9] & Steer & $\begin{array}{l}18-24 \\
\text { months }\end{array}$ & $\begin{array}{l}190-220 \\
\mathrm{~kg}\end{array}$ & $\mathrm{pH}_{\mathrm{u}}$ & $83 \%$ & N/A \\
\hline \multirow[t]{2}{*}[30]{} & $\begin{array}{l}\text { Steer } \\
\text { and }\end{array}$ & $\begin{array}{l}19.5 \\
\text { months }\end{array}$ & $335 \mathrm{~kg}$ & SSF (3 day) & $31 \%$ & 1.25 \\
\hline & heifer & & & SSF (14 day) & $23 \%$ & 1.14 \\
\hline
\end{tabular}


Table 5. Summary statistics of the quality attributes of 75 heifers.

\begin{tabular}{|c|c|c|c|c|c|c|c|c|}
\hline \multirow[t]{2}{*}{ Trait } & \multicolumn{4}{|c|}{ Calibration set for heifers } & \multicolumn{4}{|c|}{ Validation set for heifers } \\
\hline & $\mathrm{n}$ & Mean & Range & SD & $\mathrm{n}$ & Mean & Range & SD \\
\hline $\mathrm{L}^{*}$ & 56 & 37.68 & $32.61-45.39$ & 2.35 & 19 & 37.36 & $30.64-42.89$ & 2.67 \\
\hline$a^{*}$ & 56 & 25.15 & $19.11-31.40$ & 2.23 & 19 & 24.84 & $18.06-29.29$ & 2.49 \\
\hline$b^{*}$ & 56 & 9.50 & $5.24-13.54$ & 1.66 & 19 & 9.35 & $5.18-12.52$ & 1.79 \\
\hline $\mathrm{pH}_{\mathrm{u}}$ & 56 & 5.46 & $5.23-5.87$ & 0.12 & 19 & 5.44 & $5.20-5.63$ & 0.10 \\
\hline SSF & 56 & 122.59 & $77.56-312.00$ & 43.14 & 19 & 119.62 & $77.50-223.88$ & 38.03 \\
\hline
\end{tabular}

Table 6. Summary statistics of the quality attributes of 118 steers.

\begin{tabular}{|c|c|c|c|c|c|c|c|c|}
\hline \multirow[t]{2}{*}{ Trait } & \multicolumn{4}{|c|}{ Calibration set for steers } & \multicolumn{4}{|c|}{ Validation set for steers } \\
\hline & $\mathrm{n}$ & Mean & Range & SD & $\mathrm{n}$ & Mean & Range & SD \\
\hline $\mathrm{L}^{*}$ & 88 & 37.69 & $32.22-44.32$ & 2.35 & 30 & 37.64 & $32.11-43.91$ & 2.53 \\
\hline$a^{*}$ & 88 & 24.89 & $20.05-31.03$ & 2.20 & 30 & 24.82 & $19.25-29.75$ & 2.33 \\
\hline $\mathrm{b}^{*}$ & 88 & 9.29 & $4.97-13.99$ & 1.85 & 30 & 9.24 & $3.80-13.95$ & 2.09 \\
\hline $\mathrm{pH}_{\mathrm{u}}$ & 88 & 5.50 & $5.20-6.37$ & 0.19 & 30 & 5.50 & $5.18-6.15$ & 0.19 \\
\hline SSF & 88 & 114.25 & $69.83-258.85$ & 33.10 & 30 & 114.67 & $69.83-258.85$ & 37.17 \\
\hline
\end{tabular}

Table 7. Summary statistics of the quality attributes of 41 young bulls.

\begin{tabular}{|c|c|c|c|c|c|c|c|c|}
\hline \multirow[t]{2}{*}{ Trait } & \multicolumn{4}{|c|}{ Calibration set for young bulls } & \multicolumn{4}{|c|}{ Validation set for young bulls } \\
\hline & $\mathrm{n}$ & Mean & Range & SD & $\mathrm{n}$ & Mean & Range & SD \\
\hline $\mathrm{L}^{*}$ & 30 & 36.07 & $30.76-42.44$ & 2.78 & 11 & 35.93 & $27.65-43.03$ & 4.03 \\
\hline$a^{*}$ & 30 & 22.48 & $18.73-24.90$ & 1.77 & 11 & 22.73 & $14.88-32.05$ & 4.11 \\
\hline$b^{*}$ & 30 & 7.51 & $3.70-10.49$ & 1.81 & 11 & 7.75 & $2.74-13.71$ & 2.79 \\
\hline $\mathrm{pH}_{\mathrm{u}}$ & 30 & 5.65 & $5.28-6.49$ & 0.35 & 11 & 5.70 & $5.24-6.74$ & 0.47 \\
\hline SSF & 30 & 150.91 & $86.82-273.03$ & 49.06 & 11 & 156.64 & $72.77-329.39$ & 71.70 \\
\hline
\end{tabular}


Table 8. Performance of VISNIR spectroscopy for predicting instrumental meat quality in heifer M. longissimus thoracis using SVM, with noise removed spectra $(495 \mathrm{~nm}-1600 \mathrm{~nm})$.

\begin{tabular}{|c|c|c|c|c|c|c|c|c|}
\hline \multirow[t]{2}{*}{ Trait } & \multirow[t]{2}{*}{$\mathrm{PC}$} & \multicolumn{3}{|c|}{ Calibration for heifers } & \multicolumn{4}{|c|}{ Validation for heifers } \\
\hline & & $\mathrm{n}$ & $\mathrm{R}_{\text {cal }}^{2}(\%)$ & $\mathrm{RMSE}_{\mathrm{cal}}$ & $\mathrm{n}$ & $\mathrm{R}_{\text {val }}^{2}(\%)$ & $\mathrm{SE}_{\mathrm{val}}$ & $\mathrm{RPD}_{\mathrm{val}}$ \\
\hline $\mathrm{L}^{*}$ & 20 & 56 & 78.4 & 1.12 & 19 & 73.6 & 1.46 & 1.83 \\
\hline$a^{*}$ & 35 & 56 & 73.0 & 1.21 & 19 & 29.1 & 2.21 & 1.13 \\
\hline $\mathrm{b}^{*}$ & 15 & 56 & 52.3 & 1.34 & 19 & 45.2 & 1.39 & 1.29 \\
\hline $\mathrm{pH}_{\mathrm{u}}$ & 35 & 56 & 63.9 & 0.08 & 19 & 47.0 & 0.08 & 1.25 \\
\hline SSF & 2 & 56 & 96.2 & 9.85 & 19 & 27.3 & 40.91 & 0.93 \\
\hline
\end{tabular}

Table 9. Performance of VISNIR spectroscopy for predicting instrumental meat quality in steer $M$. longissimus thoracis using SVM, with noise removed spectra $(495 \mathrm{~nm}-1600 \mathrm{~nm})$.

\begin{tabular}{|c|c|c|c|c|c|c|c|c|}
\hline \multirow[t]{2}{*}{ Trait } & \multirow[t]{2}{*}{ PC } & \multicolumn{3}{|c|}{ Calibration for steers } & \multicolumn{4}{|c|}{ Validation for steers } \\
\hline & & $\mathrm{n}$ & $\mathrm{R}_{\text {cal }}^{2}(\%)$ & $\mathrm{RMSE}_{\mathrm{cal}}$ & $\mathrm{n}$ & $\mathrm{R}_{\text {val }}^{2}(\%)$ & $\mathrm{SE}_{\mathrm{val}}$ & $\mathrm{RPD}_{\text {val }}$ \\
\hline $\mathrm{L}^{*}$ & 25 & 88 & 86.6 & 0.92 & 30 & 88.7 & 1.01 & 2.50 \\
\hline$a^{*}$ & 35 & 88 & 72.5 & 1.15 & 30 & 59.4 & 1.46 & 1.60 \\
\hline$b^{*}$ & 30 & 88 & 75.2 & 0.96 & 30 & 50.4 & 1.47 & 1.42 \\
\hline $\mathrm{pH}_{\mathrm{u}}$ & 20 & 88 & 89.8 & 0.06 & 30 & 58.9 & 0.12 & 1.58 \\
\hline SSF & 2 & 88 & 71.5 & 22.58 & 30 & 5.7 & 40.35 & 0.92 \\
\hline
\end{tabular}

Table 10. Performance of VISNIR spectroscopy for predicting instrumental meat quality in young bull M. longissimus thoracis using SVM, with noise removed spectra $(495 \mathrm{~nm}-1600 \mathrm{~nm})$.

\begin{tabular}{|c|c|c|c|c|c|c|c|c|}
\hline \multirow[t]{2}{*}{ Trait } & \multirow[t]{2}{*}{$\mathrm{PC}$} & \multicolumn{3}{|c|}{ Calibration for young bulls } & \multicolumn{4}{|c|}{ Validation for young bulls } \\
\hline & & $\mathrm{n}$ & $\mathrm{R}_{\text {cal }}^{2}(\%)$ & $\mathrm{RMSE}_{\mathrm{cal}}$ & $\mathrm{n}$ & $\mathrm{R}_{\text {val }}^{2}(\%)$ & $\mathrm{SE}_{\mathrm{val}}$ & $\mathrm{RPD}_{\mathrm{val}}$ \\
\hline $\mathrm{L}^{*}$ & 4 & 30 & 80.6 & 0.21 & 11 & 93.9 & 0.98 & 4.11 \\
\hline$a^{*}$ & 25 & 30 & 97.5 & 0.30 & 11 & 63.3 & 2.57 & 1.60 \\
\hline$b^{*}$ & 4 & 30 & 50.6 & 1.27 & 11 & 54.1 & 1.97 & 1.42 \\
\hline $\mathrm{pH}_{\mathrm{u}}$ & 10 & 30 & 63.3 & 0.22 & 11 & 71.4 & 0.29 & 1.62 \\
\hline SSF & 2 & 30 & 29.6 & 41.22 & 11 & 15.0 & 63.92 & 1.12 \\
\hline
\end{tabular}


Figure 1. A plot of 10 replicate spectra $(350 \mathrm{~nm}-1800 \mathrm{~nm})$ collected from the M.longissimus thoracis of one carcass showing the noise at the extremes of the spectra.

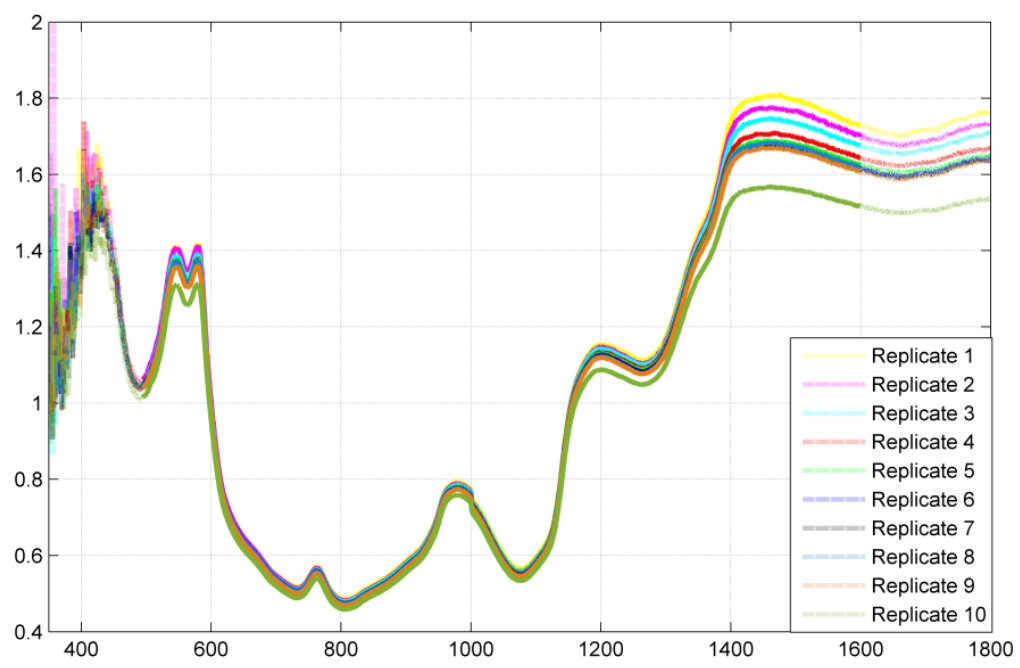

